\title{
The isopeptidase inhibitor 2cPE triggers proteotoxic stress and ATM activation in chronic lymphocytic leukemia cells
}

\author{
Andrea Tomasella ${ }^{1}$, Raffaella Picco ${ }^{1}$, Sonia Ciotti ${ }^{1}$, Andrea Sgorbissa ${ }^{1}$, Elisa Bianchi ${ }^{2}$, \\ Rossella Manfredini2, Fabio Benedetti ${ }^{3}$, Valentina Trimarco ${ }^{4}$, Federica Frezzato ${ }^{4}$, \\ Livio Trentin ${ }^{4}$, Gianpietro Semenzato4, Domenico Delia ${ }^{5}$, Claudio Brancolini ${ }^{1,2}$ \\ ${ }^{1}$ Department of Medical and Biological Sciences, Università degli Studi di Udine, Udine, Italy \\ ${ }^{2}$ Centre for Regenerative Medicine "Stefano Ferrari", Department of Life Sciences, University of Modena and Reggio Emilia, \\ Modena, Italy \\ ${ }^{3}$ Dipartimento di Scienze Chimiche e Farmaceutiche, Università degli Studi di Trieste, Trieste, Italy \\ ${ }^{4}$ Department of Medicine, Hematology and Clinical Immunology Branch, Padua University School of Medicine, Padua, Italy \\ ${ }^{5}$ Department of Experimental Oncology and Molecular Medicine, Fondazione IRCCS Istituto Nazionale dei Tumori, Milan, Italy \\ Correspondence to: Claudio Brancolini, email: claudio.brancolini@uniud.it \\ Keywords: CLL, apoptosis, proteasome, proteotoxic stress, deubuquitylases \\ Received: November 15, $2015 \quad$ Accepted: May 22, $2016 \quad$ Published: May 31, 2016
}

\section{ABSTRACT}

Relapse after treatment is a common and unresolved problem for patients suffering of the B-cell chronic lymphocytic leukemia (B-CLL). Here we investigated the ability of the isopeptidase inhibitor 2CPE to trigger apoptosis in leukemia cells in comparison with bortezomib, another inhibitor of the ubiquitin-proteasome system (UPS). Both inhibitors trigger apoptosis in CLL B cells and gene expression profiles studies denoted how a substantial part of genes up-regulated by these compounds are elements of adaptive responses, aimed to sustain cell survival. 2 cPE treatment elicits the up-regulation of chaperones, proteasomal subunits and elements of the anti-oxidant response. Selective inhibition of these responses augments apoptosis in response to $2 \mathrm{CPE}$ treatment. We have also observed that the product of the ataxia telangiectasia mutated gene (ATM) is activated in 2 CPE treated cells. Stimulation of ATM signaling is possibly dependent on the alteration of the redox homeostasis. Importantly ATM inhibition, mutations or down-modulation increase cell death in response to $2 \mathrm{CPE}$. Overall this work suggests that $2 \mathrm{CPE}$ could offer new opportunities for the treatment of B-CLL.

\section{INTRODUCTION}

B-cell chronic lymphocytic leukemia (B-CLL) is the most prevalent leukemia in Western countries and it is characterized by accumulation of malignant cells in the blood, lymph nodes, spleen and bone marrow. B-CLL is a severe disease with heterogeneous clinical course and although new therapies have significantly prolonged the overall survival, most patients relapse [1]. Augmented expression of anti-apoptotic Bcl-2 family members and up-regulation of pro-survival pathways contribute to the resistant phenotype [1-5].

Among drugs tested for the ability to trigger apoptosis in B-CLL cells, inhibitors of the ubiquitinproteasome system (UPS) have raised some interest.
Bortezomib, the first UPS inhibitor approved for the use in clinic, efficiently triggers apoptosis in in vitro cultured B-CLL cells [6, 7]. Unfortunately, clinical trials evaluating bortezomib in B-CLL patients were unsatisfactory [8]. Several constrains can explain this failure, including the chemical reaction between the boronate moiety of bortezomib and dietary flavonoids [9]. Furthermore bortezomib induces thrombocytopenia and neuropathy possibly due to proteasomal independent activities [10]. Hence, evaluating alternative compounds targeting the UPS for the treatment of B-CLL is of primary importance.

Small molecules characterized by the presence of a cross-conjugated $\alpha, \beta$-unsaturated dienone with two sterically accessible electrophilic $\beta$-carbons can act as Michael acceptors to target nucleophiles, such 
as cysteine residues [11-14]. Highly susceptible to these compounds are the isopeptidases, which contain a cysteine in the catalytic core. Isopeptidases include DUBs (deubiquitylases) and ubiquitin-like proteases. Although the presence of different groups, in addition to the pharmacophore, can enhance or limit the promiscuity of these compounds, we refer to them as partially-selective isopeptidase inhibitors (P-SIIs) [11-16].

P-SIIs are potent inducers of apoptosis and of additional types of cell death, particularly in cells showing extreme apoptotic resistance [17-19]. We have recently developed a PEG-conjugated P-SII, named 2cPE optimized for the in vivo delivery. $2 \mathrm{cPE}$ is a pro-drug version of G5 [11], which can be activated by secreted esterase and exhibits promising anti-neoplastic activities in vivo [20]. In this manuscript, we have investigated the effect of 2cPE against B-CLL cells, in comparison with bortezomib. Our results prove that induction of proteotoxic stress is a key aspect of $2 \mathrm{cPE}$ activity and discovered an unexpected contribution of ATM in influencing 2cPEinduced apoptosis.

\section{RESULTS}

\section{The UPS inhibitors bortezomib, G5 and 2cPE cause loss of viability of $\mathrm{CD}^{-} 9^{+} \mathrm{B}-\mathrm{CLL}$ cells}

Bortezomib and the isopeptidase inhibitor G5, or its PEGylated derivative 2cPE, induce loss of viability in primary CLL cells (Figure 1A and 1B). Cytofluorimetric analysis proved that, for all inhibitors, the loss of viability is largely caused by the induction of apoptosis, with only a minor fraction of the cells exhibiting markers (Annexin- $\mathrm{V}^{-}$ and $\mathrm{PI}^{+}$) of primary necrosis (Figure 1C and 1D).

\section{Gene expression profiles of B-CLL cells treated with the UPS inhibitors bortezomib and 2cPE}

To explore whether bortezomib and 2cPE elicit similar or different biological responses, we performed microarray experiments in primary B-CLL cells. Leukemia CD $19^{+}$B-cells from 10 different patients were treated or not for 3, 6, 12 and 24 hours with $6 \mathrm{nM}$ of bortezomib or with $4 \mu \mathrm{M}$ of $2 \mathrm{cPE}$. Under these conditions the two compounds induce equivalent levels of apoptosis, at 24 hours. For the microarray analysis the 6 hours time-point was selected in order to observe early adaptive responses to the inhibitors and to exclude changes in mRNA expression depending on cellular demise. The clinical and prognostic features of each of the 10 primary CLL samples and their responsiveness in terms of apoptosis are described in Table 1.

Data analysis identified a list of common genes, which expression is influenced by both compounds. Venn diagrams (Figure 2A) illustrate that only few genes were commonly modulated by $2 \mathrm{cPE}$ and bortezomib in different patients (19 up-regulated and 15 down-regulated). Overall $2 \mathrm{cPE}$ influences the expression of a wider number of genes compared to bortezomib, 169 and 95 genes respectively, including both up and down-regulated ones.

The vast majority of the commonly up-regulated genes encode for chaperones implicated in the regulation of protein folding (Figure 2B). A second group of genes comprises proteasome subunits. Interestingly among the commonly down-regulated genes, metabolic elements and components of signaling pathways can be found.

It is known that the level of proteasomal subunits can influence responsiveness to bortezomib treatment [21-23]. Hence, we compared changes in the expression levels of all proteasomal genes. Up-regulation of mRNAs encoding for several proteasomal subunits is a mark of the response to both inhibitors. This response was more pronounced in the case of bortezomib, whereas the downregulation of the immunoproteasome subunits PSMB8, PSMB9 and PSMB10 was comparable or even more evident in 2cPE treated cells.

The GO enrichment analysis for 2cPE and bortezomib regulated genes (Table 2 ) showed that the two drugs can elicit common but also distinct responses. Over-representations of processes such as protein folding, response to unfolded protein and response to organic substance characterize the genetic programs activated by $2 \mathrm{cPE}$. Instead after bortezomib treatment, proteasome complex and regulation of E3 ligase activity are the most represented categories. Comparative analysis of the GO terms enrichment confirmed that the response to $2 \mathrm{cPE}$ treatment is strongly characterized by the up-regulation of chaperones, whereas the response to bortezomib is highly represented by UPS components (Supplementary Table S1).

\section{Adaptive responses are engaged in B-CLL cells after 2cPE treatment}

The microarray studies suggest that a substantial part of genes up-regulated in response to $2 \mathrm{cPE}$ are elements of adaptive programs aimed to sustain cell survival. These programs include the accumulation of new proteasomal units, to overcome its obstruction, the up-regulation of chaperones, to counteract misfolding and the potentiation of the anti-oxidant capabilities. In addition, $2 \mathrm{cPE}$ triggers also the down-regulation of some signaling pathways. To validate our studies we performed qRT-PCR analysis on four different genes, archetypes of the adaptive responses engaged by $2 \mathrm{cPE}$. Three selected genes were up-regulated: GCLM, HMOX1, SQSTM1/p62, whereas the fourth gene, $L C K$, was down-regulated. Supplementary Table $\mathrm{S} 2$ shows the average fold induction and the correlation analysis, respect to the induction of apoptosis in the different B-CLL, for these genes.

GCLM (glutamate cysteine ligase modifier) encodes for the component of the glutamate cysteine ligase (GCL), the enzyme responsible for glutathione (GSH) synthesis. 
Both subunits were increased after $2 \mathrm{cPE}$ treatment. The heme oxygenase-1 (HMOX1) encodes for an ubiquitous enzyme that supervises cytoprotective responses to toxic insults [24]. SQSTM1/p62/sequestosome encodes for a scaffold protein functioning as signaling hub in different pathways including autophagy [25]. Finally, $L C K$ encodes for the T-cell-specific member of the Src family of tyrosine kinase, which is also expressed in B-CLL [26]. The qRTPCR analysis corroborated the regulation of these genes in response to $2 \mathrm{cPE}$ treatment (Supplementary Figure S1).

We next confirmed these data in human chronic B-cell leukemia, MEC-1 cells. The 2cPE pro-drug and its unconjugated version, $2 \mathrm{c}$ induce comparable levels of cell death (Figure $3 \mathrm{~A}$ ), thus indicating that this cell line
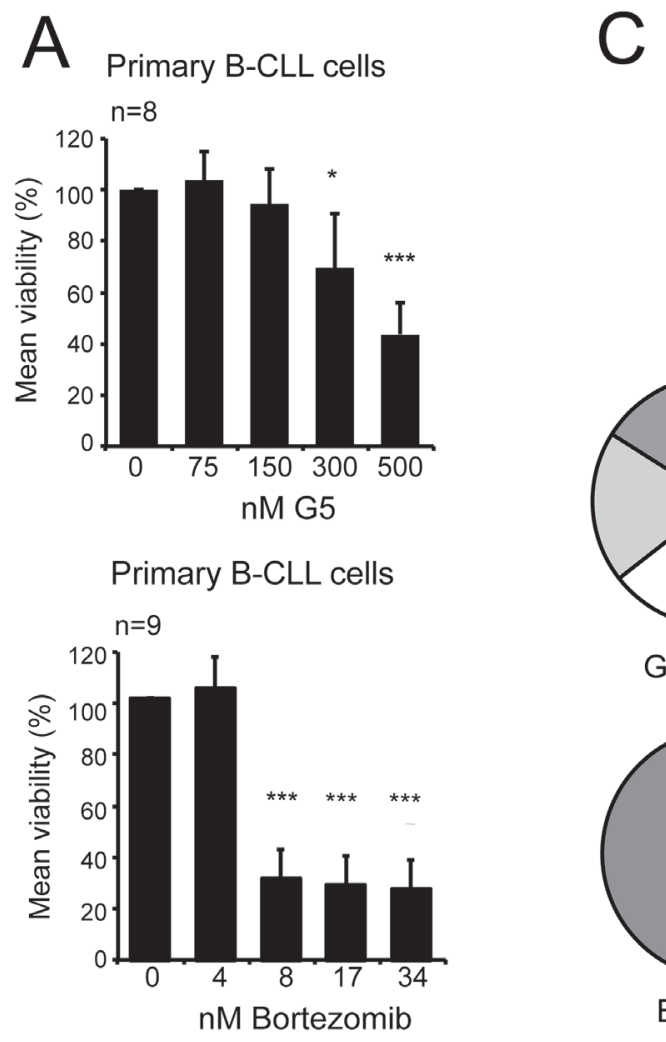

Primary B-CLL cells $\mathrm{n}=8$

- Necrosis $\square$ Secondary/primary necrosis $\square$ Apoptotic $\square$ Healty

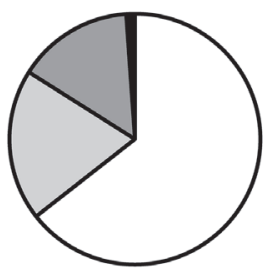

G5 150nM

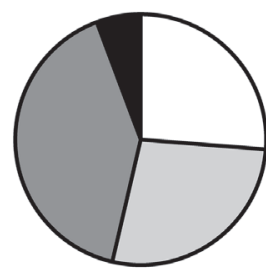

Bort. 8nM

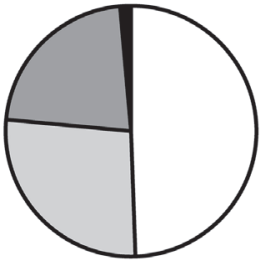

G5 300nM

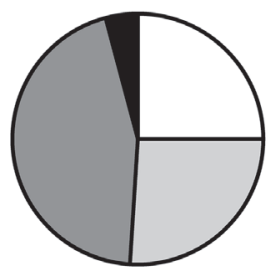

Bort. 17nM

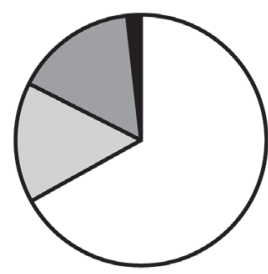

Untreated

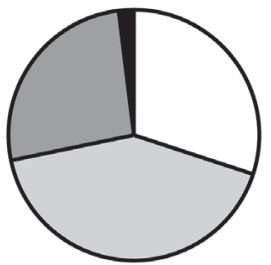

G5 500nM

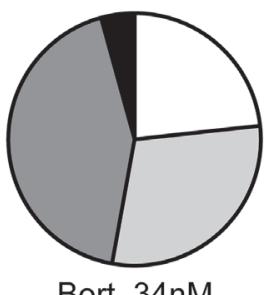

Bort. 34nM

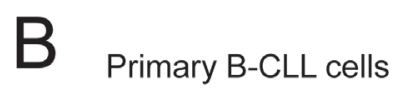

Primary B-CLL cells $n=6$
Necrosis
$\square$ Secondary/primary necrosis

Apoptotic

$\square$ Healty
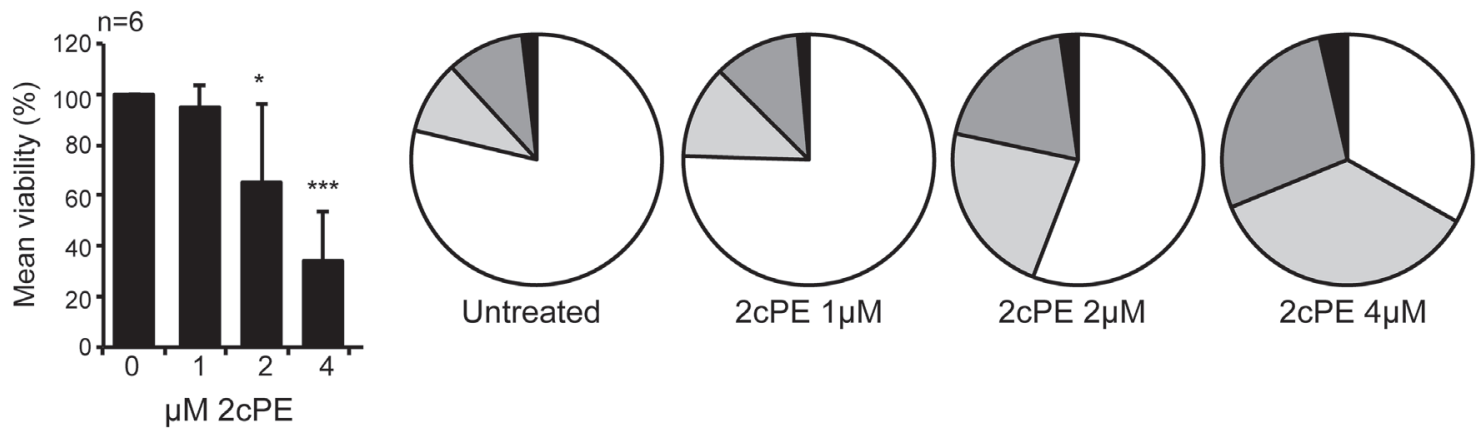

Figure 1: Pro-apoptotic activity of bortezomib, the P-SII G5 and its pro-drug derivative 2cPE in primary B-CLL cells. A. Primary B-CLL cells viability following treatment with escalating doses of G5 or bortezomib for 24 hours as indicated. Cell viability was calculated as percentage of cells negative to PI and Annexin V staining after cytofluorimetric analysis. B. Flow cytometry analysis for apoptotic markers (Annexin V/PI) in order to define the type of cell death. Primary B-CLL cells were treated with the indicated concentrations of bortezomib or G5 for 24 hours. C. Primary B-CLL cells viability following treatment with escalating doses of $2 \mathrm{cPE}$ for 24 hours as indicated. Cell viability was calculated as the percentage of cells negative to PI and Annexin V staining after cytofluorimetric analysis. D. Flow cytometry analysis for apoptotic markers (Annexin V/PI) in order to define the type of cell death. Primary B-CLL cells were treated with the indicated concentrations of $2 \mathrm{cPE}$ for 24 hours. Columns, mean loss of viability $+\mathrm{SD} . *=\mathrm{p}<0.05$; $* *=\mathrm{p}<0.01$; $* * * \mathrm{p}=<0.005$. 
Table 1: Clinical characteristics, apoptotic response, mutational status and genetic alterations of the included patients

\begin{tabular}{lccccccc}
\hline code & Sex/age & IGHV & FISH & RAI stage & CD38 & 2cPE & Bortezomib \\
\hline LL300 & F/79 & U & $13 q-$ & II & NEG & 88 & 89 \\
LLC122 & M/66 & U & $11 \mathrm{q}-$ & 0 & POS & 15 & 59 \\
LLC195 & M/69 & U & $11 \mathrm{q}-; 13 q-$ & II & POS & 2 & 86 \\
LLC351 & M/67 & U & $17 q-; 13 q-$ & I & POS & 81 & 92 \\
LLC270 & M/73 & U & $11 q-$ & II & POS & 17 & 65 \\
LLC4 & F/73 & M & $*$ & I & NEG & 82 & 81 \\
LLC305 & M/56 & M & Normal & 0 & NEG & 75 & 54 \\
LLC366 & F/69 & $*$ & $13 q-; 12+; p 53$ mut & 0 & POS & 45 & 77 \\
LLC37 & F/79 & M & $13 q-$ & II & NEG & 8 & 38 \\
LLC43 & M/83 & M & $12+$ & I & POS & 68 & 82 \\
& & & & & & Apoptosis at 24 hours (\%) \\
\hline
\end{tabular}

Note: The gender of the patients, the IgHV mutational status ( $\mathrm{U}=$ unmutated, $\mathrm{M}=$ mutated), $\mathrm{CD} 38$ expression (POS = positive for $\mathrm{CD} 38$ expression; $\mathrm{NEG}=$ negative $\mathrm{CD} 38$ expression), the cytogenetic alterations observed and the $\%$ of apoptosis after 24 of treatment with the indicated drugs for each patient sample are shown.

* indicates that the status of a specific characteristic for a patient is unknown.

secretes the esterase PLA2G7 [20]. 2c and 2cPE induced cell death was apoptotic, as confirmed by the caspasedependent proteolytic cleavage of the death substrate GAS2 (Figure 3B) [27]. In MEC-1 cells, similarly to primary B-CLL cells, 2cPE treatment up-regulates the expression of HMOX1, GSLM as well as of SQSTM1 and down-regulates $L C K$ mRNA levels (Figure 3C).

HMOX1, GCLM and SQSTM1 are components of the cytoprotective response to oxidative stress and, likewise other genes induced after $2 \mathrm{cPE}$ treatment, they are under the control of the transcription factor NRF2 [28, $29]$. Figure $3 \mathrm{D}$ proves that $2 \mathrm{cPE}$ treatment augmented NRF2 levels in MEC-1 cells.

\section{Inhibition of the adaptive responses elicited by $2 \mathrm{cPE}$ and effects on cell death}

Several of 2cPE differentially expressed genes (DEGs) boost adaptive responses devoted for sustaining cell survival. Hence, suppressing these adaptive responses should potentiate apoptosis in response to $2 \mathrm{cPE}$. To verify this hypothesis we co-treated MEC-1 cells with 2cPE in combination with buthionine sulfoximine (BSO), a selective inhibitor of $\gamma$-glutamylcysteine synthetase, or with the geldanamycin derivative 17-AAG, an inhibitor of HSP90. BSO alone was unable to trigger cell death but at highest doses it potentiated the pro-death effect of $2 \mathrm{cPE}$, as scored by both PI positivity and caspase activity (Figure 4A). When the ROS generator DMNQ was used, as positive control, the cooperative effect of BSO was more evident (Figure 4A). Treatment with 17-AGG alone induces apoptosis in approximately $30 \%$ of cells, independently from the applied dose. When MEC-1 cells pre-incubated with escalating doses of 17-AGG were cotreated with 2cPE, cell death as well as the intensity of caspase activation, were significantly augmented (Figure 4B). Similarly, also bortezomib induced cell death was augmented in the presence of the HSP90 inhibitor (Figure 4B).

Down-regulation of LCK expression might be an important event for the pro-apoptotic activity of $2 \mathrm{cPE}$. Also in this case treatment with an LCK inhibitor (LCKi) might exhibit an additive effect with $2 \mathrm{cPE}$. Figure $3 \mathrm{C}$ evidences that co-treatment with $2 \mathrm{cPE}$ and LCKi potentiates apoptosis and caspase activation in response to $2 \mathrm{cPE}$.

\section{Markers of responsiveness to $2 \mathrm{cPE}$ treatment}

The apoptotic responsiveness of B-CLL cells from the different patients to 2cPE is heterogeneous (Table 1). Some cells are highly susceptible and others are resistant. Hence, we decided to use the pattern of all DEGs in all patients to discover markers of $2 \mathrm{cPE}$ responsiveness. The lists of DEGs were fused and used to extract the values of single patient differences (fold changes $>1.5<-1.5$; $P$ values $<0.05$ ). An unsupervised clustering analysis was performed and the results are presented as heat map (Figure 5). The apoptotic responsiveness of the different leukemic B-cells is displayed by a colour code. The 


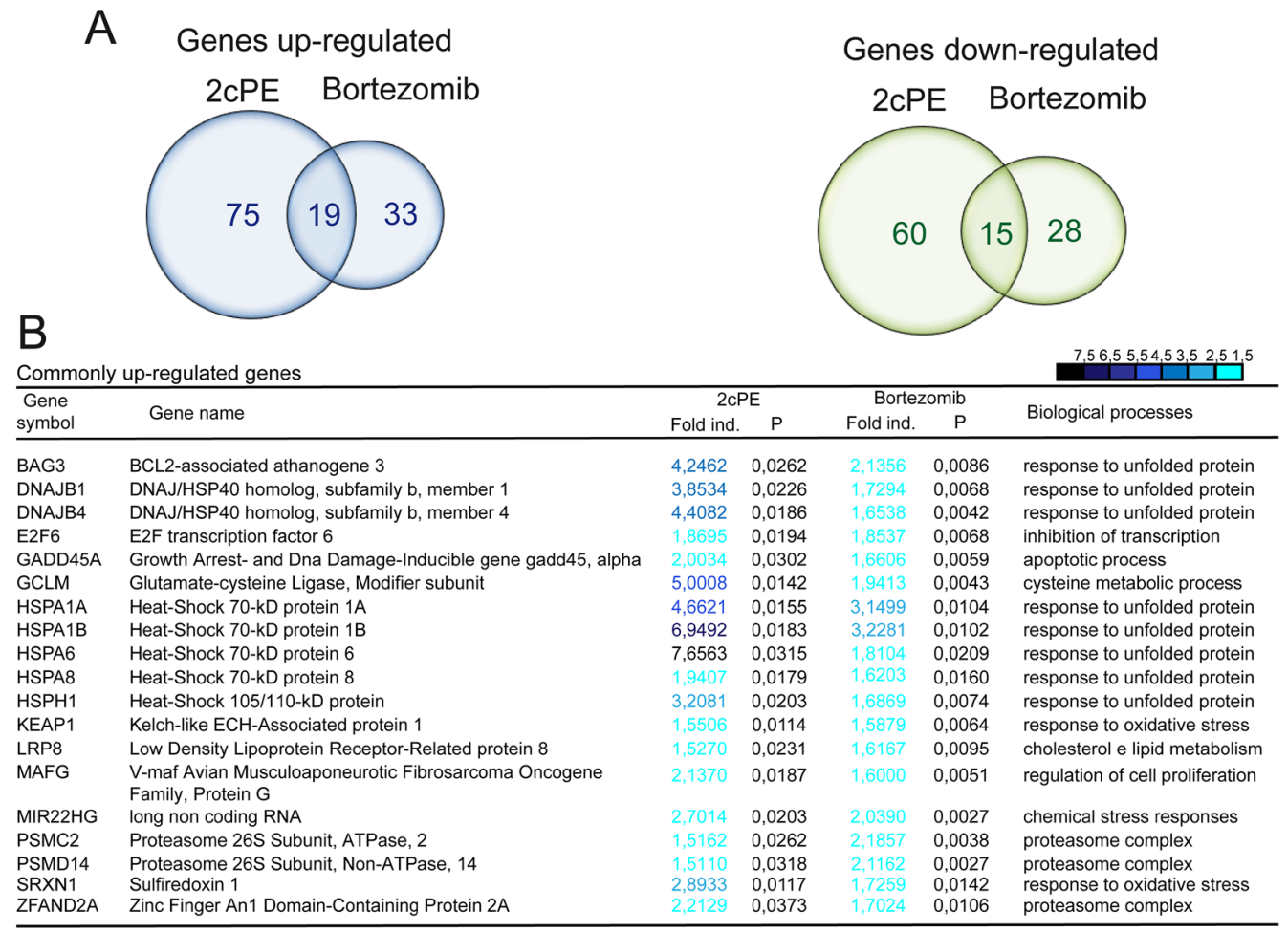

\begin{tabular}{|c|c|c|c|c|c|c|}
\hline \multirow{2}{*}{$\begin{array}{l}\text { Gene } \\
\text { symbol }\end{array}$} & \multirow[b]{2}{*}{ Gene name } & \multicolumn{2}{|c|}{$2 \mathrm{CPE}$} & \multicolumn{2}{|c|}{ Bortezomib } & \multirow[b]{2}{*}{ Biological processes } \\
\hline & & Fold ind. & $\mathrm{P}$ & Fold ind. & $\mathrm{P}$ & \\
\hline ADA & Adenosine Deaminase & $-1,6760$ & 0,0318 & $-1,6127$ & 0,0477 & metabolic process \\
\hline AKAP5 & A-Kinase Anchor Protein 5 & $-1,6535$ & 0,0245 & $-1,6217$ & 0,0116 & energy reserve metabolic process \\
\hline BTLA & B- and T-Lymphocyte Attenuator & $-1,6378$ & 0,0492 & $-1,5515$ & 0,0052 & lymphocyte costimulation \\
\hline DUSP4 & Dual-Specificity Phosphatase 4 & $-2,1808$ & 0,0059 & $-1,9980$ & 0,0213 & inactivation of MAPK activity \\
\hline ENC1 & Ectodermal-Neural Cortex 1 & $-1,7000$ & 0,0170 & $-1,5824$ & 0,0146 & actin cytoskeleton \\
\hline FAM111B & Family with Sequence Similarity 111, Member B & $-1,7306$ & 0,0200 & $-1,6207$ & 0,0094 & metabolic process \\
\hline GAPT & GRB2-Binding Adaptor Protein, Transmembrane & $-1,7190$ & 0,0283 & $-1,6868$ & 0,0079 & B cell activation \\
\hline IL2RA & Interleukin 2 Receptor, Alpha & $-1,7765$ & 0,0228 & $-1,6484$ & 0,0189 & lymphocyte homeostasis \\
\hline LILRB2 & Leukocyte Immunoglobulin-like Receptor, Subfamily B, Member 2 & $-1,6349$ & 0,0296 & $-1,6981$ & 0,0318 & positive regulation of tolerance \\
\hline MS4A7 & Membrane-Spanning 4-Domains, Subfamily A, Member 7 & $-1,6022$ & 0,0291 & $-1,9534$ & 0,0400 & unknown \\
\hline PVRIG & Poliovirus Receptor Related Immunoglobulin Domain Containing & $-2,3021$ & 0,0262 & $-2,0139$ & 0,0041 & unknown \\
\hline PYCARD & Pyd And Card Domain-containing Protein & $-1,6480$ & 0,0224 & $-1,5048$ & 0,0223 & immunw response \\
\hline RGCC & Regulator of Cell Cycle & $-1,5693$ & 0,0190 & $-1,5511$ & 0,0256 & Cell cycle \\
\hline RNASE6 & Ribonuclease, Rnase A Family, 6 & $-1,9681$ & 0,0205 & $-1,6640$ & 0,0142 & RNA catabolic process \\
\hline SOWAHD & Sosondowah Ankyrin Repeat Domain Family Member D & $-1,7865$ & 0,0286 & $-1,5023$ & 0,0158 & unknown \\
\hline
\end{tabular}

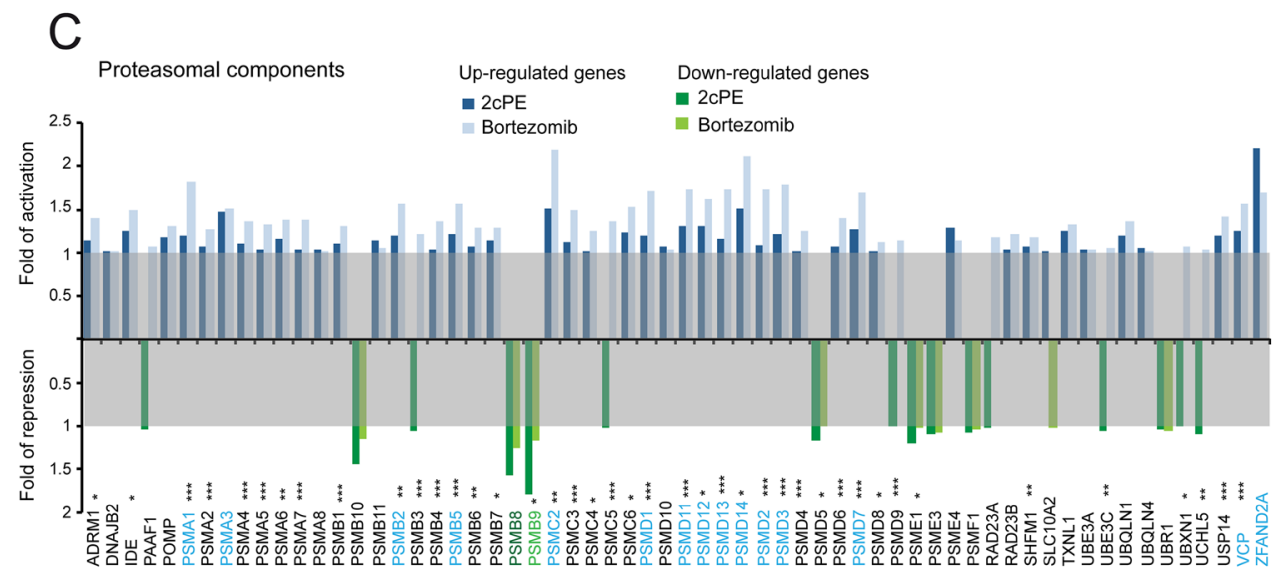

Figure 2: mRNA expression profiling of bortezomib and 2cPE treated B-CLL cells. A. Venn diagram of commonly down (green) and up-regulated (blue) genes (fold changes $>1.5 ; P$ values $<0.01$ ) using the paired t-test, in leukemic B-cell from 10 different patients after $2 \mathrm{cPE}$ and bortezomib treatments. B. List in alphabetic order of the commonly up- and down-regulated genes in leukemic B-cells form the different patients in response to $2 \mathrm{cPE}$ and bortezomib treatments (mRNA fold changes $>1.5 ;<-1.5$ ). In the heat map positive values are displayed in blue and negative in dark green. A colour code was selected to illustrate the fold changes. C. mRNA fold changes of the different proteasomal components after $2 \mathrm{cPE}$ and bortezomib treatments as indicated by the different colours. 
Table 2: GO-Terms enrichment analysis

\begin{tabular}{|c|c|c|c|c|c|c|}
\hline \multicolumn{7}{|c|}{ Gene enrichment analysis in 2 cPE treated primary B-CLL cells } \\
\hline GO-Term & Count & $\%$ & p Value & Benjamini & FDR & Fold Enr \\
\hline $\begin{array}{l}\text { GO:0006986 response } \\
\text { to unfolded protein }\end{array}$ & 13 & 8,33 & $1,66 \mathrm{E}-12$ & $2,67 \mathrm{E}-09$ & $2,78 \mathrm{E}-09$ & 19,82 \\
\hline $\begin{array}{l}\mathrm{GO}: 0051789 \sim \text { response } \\
\text { to protein stimulus }\end{array}$ & 13 & 8,33 & $3,90 \mathrm{E}-07$ & $1,96 \mathrm{E}-07$ & $4,08 \mathrm{E}-07$ & 13,15 \\
\hline $\begin{array}{l}\text { GO:0050865 regulation } \\
\text { of cell activation }\end{array}$ & 14 & 8,97 & $7,16 \mathrm{E}-09$ & $3,84 \mathrm{E}-06$ & $1,20 \mathrm{E}-05$ & 8,66 \\
\hline $\begin{array}{l}\text { GO:0010033 response } \\
\text { to organic substance }\end{array}$ & 25 & 16,02 & $3,11 \mathrm{E}-08$ & $1,25 \mathrm{E}-05$ & $5,21 \mathrm{E}-05$ & 3,75 \\
\hline $\begin{array}{l}\text { GO:0006457 protein } \\
\text { folding }\end{array}$ & 13 & 8,33 & $7,73 \mathrm{E}-08$ & $1,75 \mathrm{E}-05$ & 0,00013 & 7,94 \\
\hline $\begin{array}{l}\text { GO:0042981 regulation } \\
\text { of apoptosis }\end{array}$ & 25 & 16,02 & $2,38 \mathrm{E}-07$ & $4,80 \mathrm{E}-05$ & 0,0004 & 3,37 \\
\hline \multicolumn{7}{|c|}{ Gene enrichment analysis in Bortezomib treated primary B-CLL cells } \\
\hline GO-Term & Count & $\%$ & p Value & Benjamini & FDR & Fold Enr \\
\hline $\begin{array}{l}\text { GO:0000502 proteasome } \\
\text { complex }\end{array}$ & 14 & 15,73 & $4,31 \mathrm{E}-18$ & $5,26 \mathrm{E}-16$ & $4,97 \mathrm{E}-15$ & 42,52 \\
\hline $\begin{array}{l}\text { GO:0051351 positive } \\
\text { regulation of ligase } \\
\text { activity }\end{array}$ & 15 & 16,85 & $1,35 \mathrm{E}-18$ & $1,16 \mathrm{E}-15$ & $2,09 \mathrm{E}-15$ & 37,56 \\
\hline $\begin{array}{l}\text { GO: } 0043161 \sim \text { proteasomal } \\
\text { protein catabolic process }\end{array}$ & 15 & 16,85 & $1,91 \mathrm{E}-16$ & $1,91 \mathrm{E}-14$ & $3,44 \mathrm{E}-13$ & 26,88 \\
\hline
\end{tabular}

hierarchical clustering evidences a strong correlation between the magnitude of changes in DEGs and the induction of cell death. In the case of $2 \mathrm{cPE}$ treatment, with the exclusion of patient LLC37, all B-CLL cells responsive to $2 \mathrm{cPE}$ in terms of apoptosis, cluster together and show elevated fluctuations of DEGs. On the other side, B-CLL cells, which are resistant to $2 \mathrm{cPE}$ treatment evidence fewer transcriptional changes and cluster together. The only exception concerns leukemic cells of patient LLC37, which are resistant to $2 \mathrm{cPE}$ treatment but cluster together with responsive cells. Interestingly, LLC37 cells are also partially resistant to bortezomib.

\section{Resistance to 2cPE induced apoptosis in B-CLL cells from patients LLC122, LLC195 and LLC270}

The resistance to 2cPE-induced apoptosis, observed in some leukemia B-cells (LLC122, LLC195 and LLC270) is tightly correlated to much lower variations in the transcriptome. This failure could arise from an incapability to process the pro-drug $2 \mathrm{cPE}$ in the extracellular environment, as observed in certain cancer cells [20]. mRNA expression levels analysis of PLAG7, the secreted esterase responsible for $2 \mathrm{cPE}$ pro-drug maturation, excludes this hypothesis (Supplementary Figure S2).

Alternatively, resistance to $2 \mathrm{cPE}$ could arise from a common mRNA signature, as generated during disease progression, through the accumulation of peculiar genetic alterations. This signature should predict drugresponsiveness. To verify this possibility, we performed hierarchical gene clustering analysis, of gene expression profiles of untreated B-CLL cells from all patients. Figure $6 \mathrm{~A}$ shows that, the B-CLL cells of the three patients resistant to $2 \mathrm{cPE}$ treatment cluster together. Next, a standard t-test was performed to rank DEGs between $2 \mathrm{cPE}$ unresponsive $(n 3)$ and the responsive leukemia cells $(n 7)$ (Figure 6B). The ATM gene provided the best score ( $P$ value 2.9306E-005; fold change -1.87). In accordance, all three patients-derived B-CLL cells display the $11 \mathrm{q}$ deletion, which affects the ATM locus [30]. Other two genes, NPAT and CUL5 lie in the same chromosome region and they also scored a significant reduction in terms of expression in the non-responsive patients $(P$ value 0.0035 ; fold change -1.69 and $P$ value 0.0020 ; fold change -1.64 , respectively). 
A

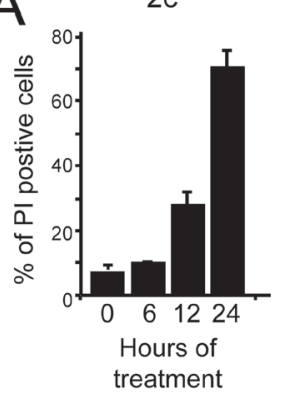

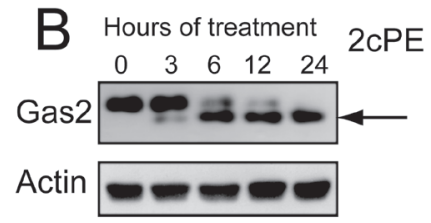
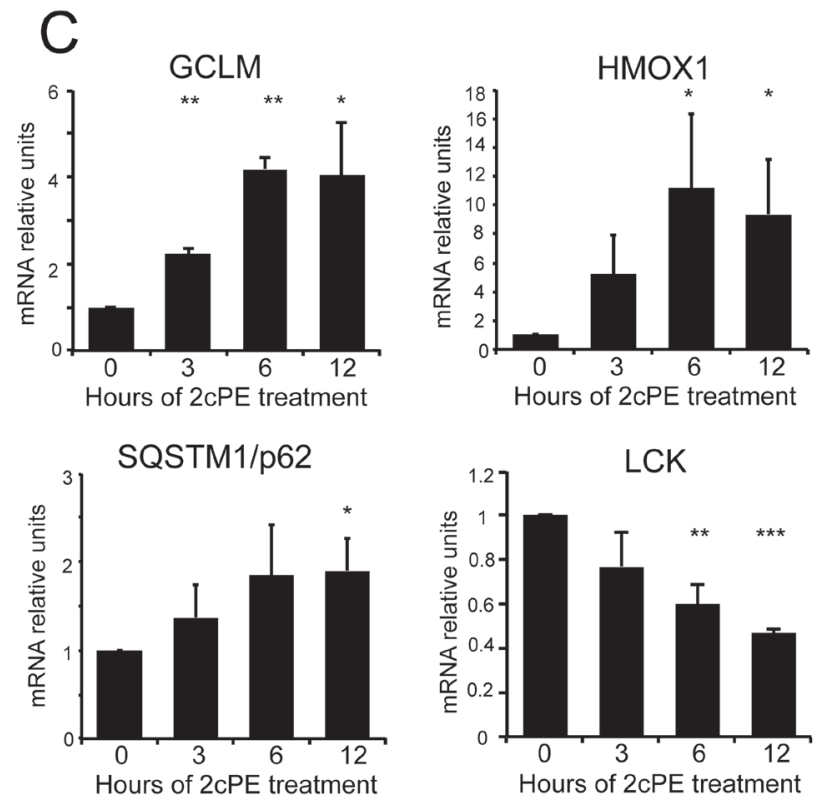

Hours of $2 \mathrm{cPE}$ treatment

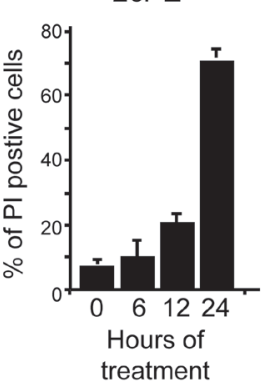

Hours of 2 cPE treatment

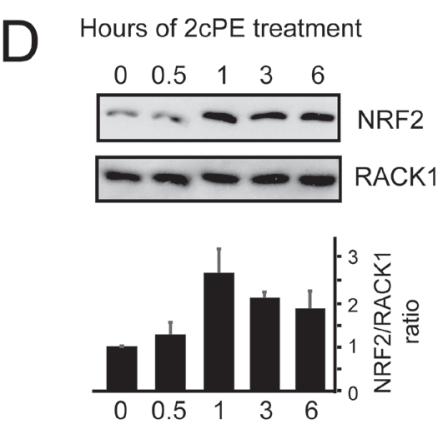

Figure 3: Adaptive responses elicited by 2 cPE in MEC-1 cells. A. Induction of cell death in MEC-1 cells after treatment for the indicated times with $2 \mathrm{c}(2 \mu \mathrm{M})$ or $2 \mathrm{cPE}(4 \mu \mathrm{M})$. Cell viability was calculated as percentage of cells positive to PI staining using cytofluorimetric analysis. B. Caspase-dependent processing of the death substrate Gas2 in MEC-1 cells treated for the indicated times with $4 \mu \mathrm{M}$ of $2 \mathrm{cPE}$. Cellular lysates were generated and subjected to immunoblot analysis. Antibodies anti-Gas2 and anti-actin (as loading control) were used. C. Time-course analysis of HOMX, GCLM, SQSTM and LCK mRNA expression levels. MEC-1 cells were treated $4 \mu \mathrm{M}$ of $2 \mathrm{cPE}$ for the indicated times and the mRNA levels were monitored by qRT-PCR. All reactions were done in triplicate. D. Immunoblot and densitometric analysis of NRF2 levels in MEC-1 cells treated for the indicated times with $4 \mu \mathrm{M}$ of $2 \mathrm{cPE}$. Cellular lysates were generated and subjected to immunoblot analysis using the indicated antibodies. Data were from 2 experiments. Columns, mean loss of viability $+\mathrm{SD}$. $*=\mathrm{p}<0.05$; $* *=\mathrm{p}<0.01 ; * * * \mathrm{p}=<0.005$ 
Since ATM is an important signaling molecule, we decided to study whether this kinase is activated in response to $2 \mathrm{cPE}$. Figure $7 \mathrm{~A}$ demonstrates that the ATM pathway is activated in response to $2 \mathrm{cPE}$, as proved by the phosphorylation of the ATM substrates KAP1, Smc1, Chk2 and p53. The 2cPE-mediated activation of ATM prompted us to evaluate the induction of DNA doublestrand breaks. Different concentrations of etoposide were used to induce DSBs and ATM activation. $4 \mu \mathrm{M}$ of $2 \mathrm{cPE}$ and $2.5 / 5 \mu \mathrm{M}$ of etoposide elicited ATM activation at comparable intensities, as scored by KAP1 phosphorylation (Figure 7B). A robust increase of $\gamma \mathrm{H} 2 \mathrm{AX}$ positivity (a marker of DSBs) can be appreciated in cells treated with 2.5 or $5 \mu \mathrm{M}$ of etoposide. By contrast, only a modest but significant increase in $\gamma \mathrm{H} 2 \mathrm{AX}$ positivity was triggered by $2 \mathrm{cPE}$ treatment (Figure $7 \mathrm{C}$ ). We confirmed these data by a time-course analysis. Again a modest, compared to etoposide, but significant increase in $\gamma \mathrm{H} 2 \mathrm{AX}$ was detectable in 2cPE treated cells at 6 hour (Figure 7D).

Next we investigated the contribution of ATM in 2cPE-induced gene expression changes. Inhibition of the ATM kinase using the specific inhibitor KU-55933 did not influenced the 2cPE-mediated up-regulation of GCLM, HOMX, SQSTM1 and the down-regulation
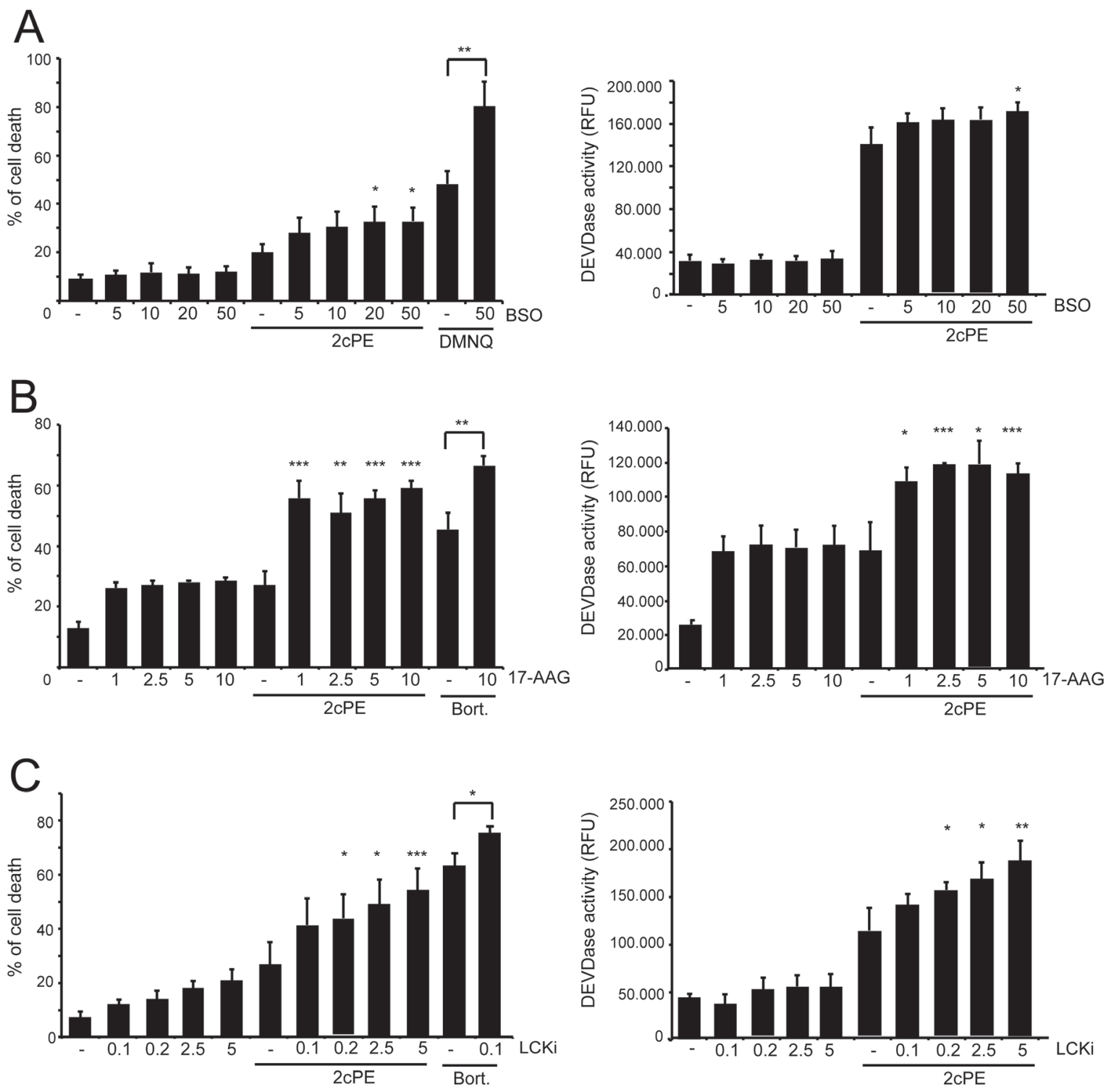

Figure 4: Interfering with the different adaptive responses elicited by $\mathbf{2 c P E}$ augmented the apoptotic response. A. MEC1 cells were pre-treated with the indicated concentrations $(\mu \mathrm{M})$ of BSO, for $24 \mathrm{~h}$. Next, $2 \mathrm{cPE}(1 \mu \mathrm{M})$, DMNQ $(20 \mu \mathrm{M})$ were added for further $24 \mathrm{~h}$. B. MEC-1 cells were pre-treated with the indicated concentrations $(\mu \mathrm{M})$ of 17 -AAG for $1 \mathrm{~h}$. Next, $2 \mathrm{cPE}(1 \mu \mathrm{M})$, bortezomib $(0.5 \mu \mathrm{M})$ were added for further $24 \mathrm{~h}$. C. MEC-1 cells were pre-treated with the indicated concentrations $(\mu \mathrm{M})$ of LCKi for $16 \mathrm{~h}$. Next, $2 \mathrm{cPE}(1 \mu \mathrm{M})$, bortezomib $(0.5 \mu \mathrm{M})$ were added for further $24 \mathrm{~h}$. Cell death was scored by PI staining using cytofluorimetric analysis and caspase activity was measured in parallel. Columns, mean $(n=3)$; bars, SD. ${ }^{*}=\mathrm{p}<0.05 ; * *=\mathrm{p}<0.01 ; * * * \mathrm{p}=<0.005$. 
of $L C K$ (Figure 7E). Surprisingly, when the effect on cell survival was evaluated, the ATM inhibitor strongly potentiated apoptosis in response to $2 \mathrm{cPE}$ (Figure 8A). To confirm this result we used ataxia telangiectasia (AT)derived lymphoblastoid cell lines (AT-LCLs) WT or lacking ATM protein expression, due to the homozygous mutation AT-52RM [31]. Figure 8B illustrates that cells lacking ATM expression are more sensitive to death induced by $2 \mathrm{cPE}$ treatment. Finally, we also generated MEC-1 cells with down-regulated ATM expression after lentiviral infections with a specific shRNA (Figure 8C). MEC-1 cells with down-regulated ATM were more susceptible to apoptosis after $2 \mathrm{cPE}$ treatment (Figure 8D).

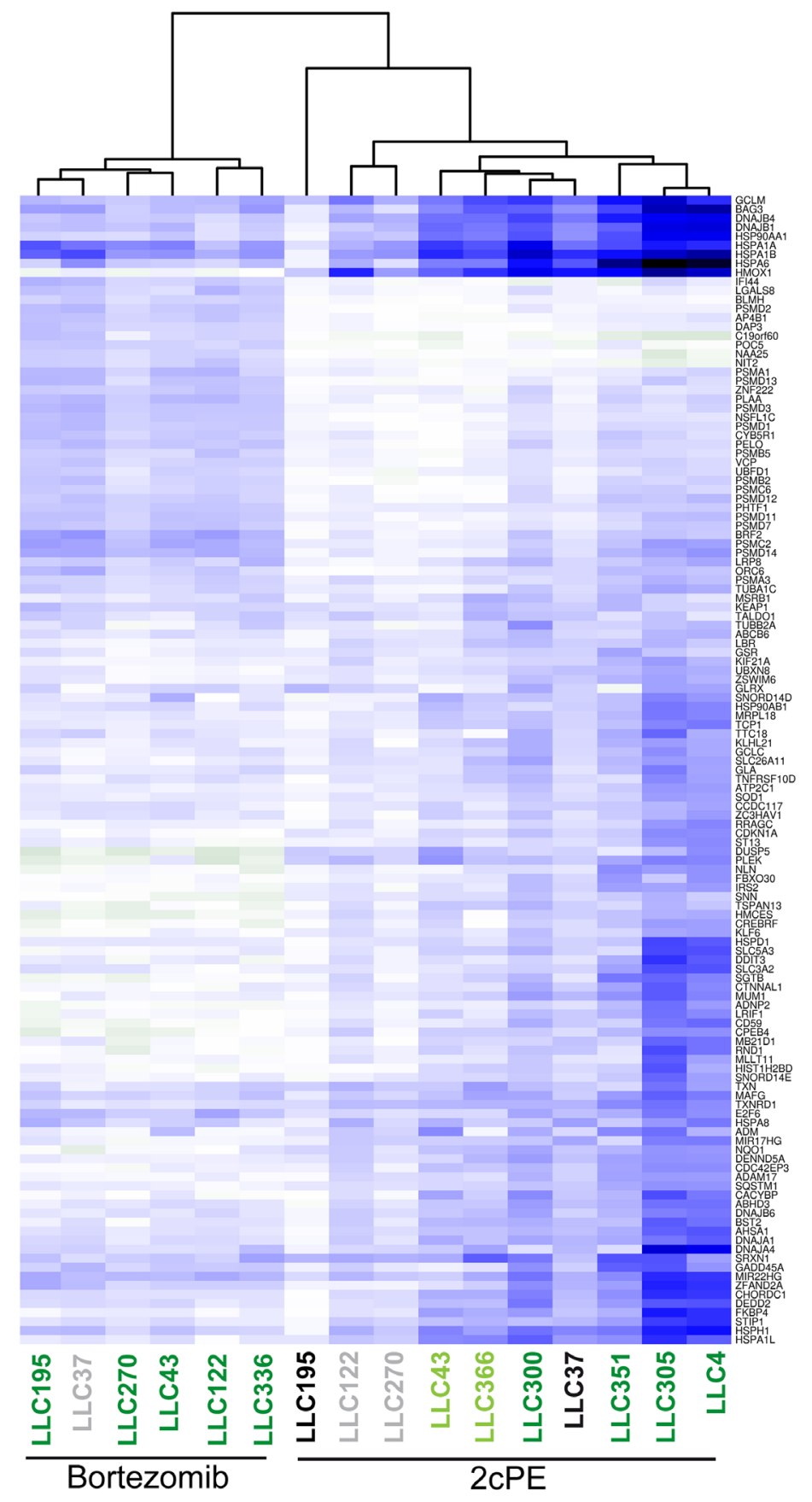

Figure 5: Resistance to 2cPE induced apoptosis correlates with the magnitude of changes in DEGs. DEGs induced by $2 \mathrm{cPE}$ or bortezomib treatments in B-CLL cells were hierarchically clustered as described in the material and methods. In the heat map up-regulated genes are displayed in blue and down-regulated genes in dark green. A colour code was used to represent the apoptotic responsiveness to $2 \mathrm{cPE}$ and bortezomib of the different B-CLL cells. Apoptosis $>75 \%$ (dark green); apoptosis between $46-74 \%$ (light green) apoptosis $<20 \%$ (grey) apoptosis $<10 \%$ (black). 


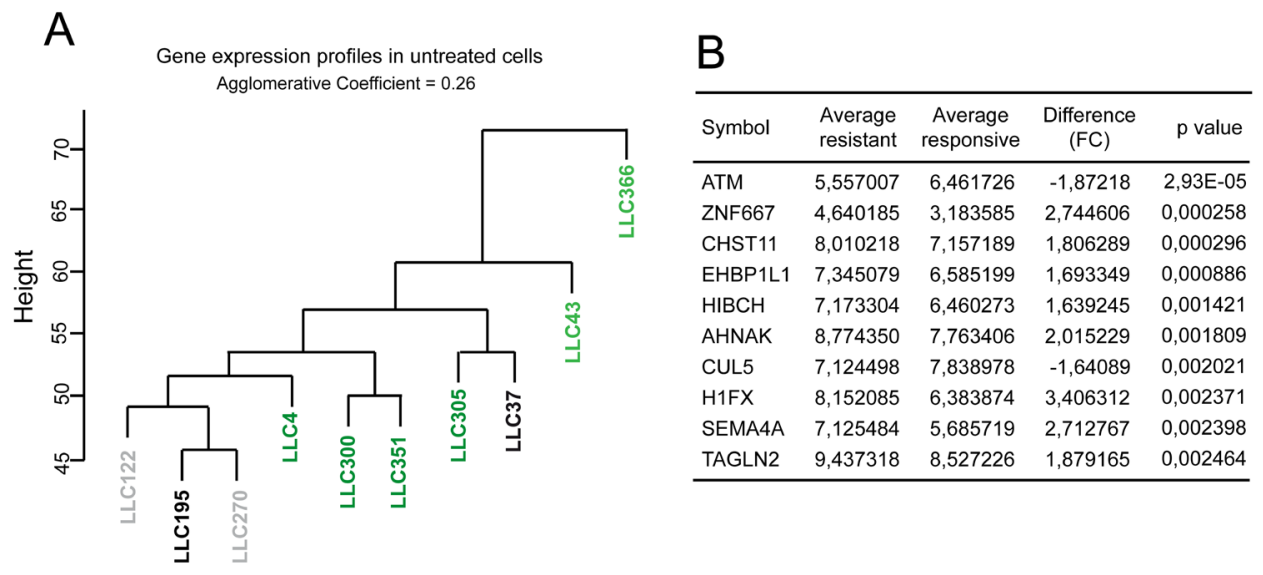

Figure 6: ATM and the resistance to 2cPE. A. Hierarchical clustering of gene expression profiles of untreated B-CLL cells from the different patients. A colour code was used to represent the apoptotic responsiveness to 2cPE and bortezomib of the different B-CLL cells. Apoptosis $>75 \%$ (dark green); apoptosis between $46-74 \%$ (light green) apoptosis $<20 \%$ (grey) apoptosis $<10 \%$ (black). B. 10 top DEGs in untreated B-CLL cells from patients LLC122, LLC195 and LLC270 compared to the untreated leukemia cells, responsive to $2 \mathrm{cPE}$, from all other patients. DEGs were ranked for $P$ value.
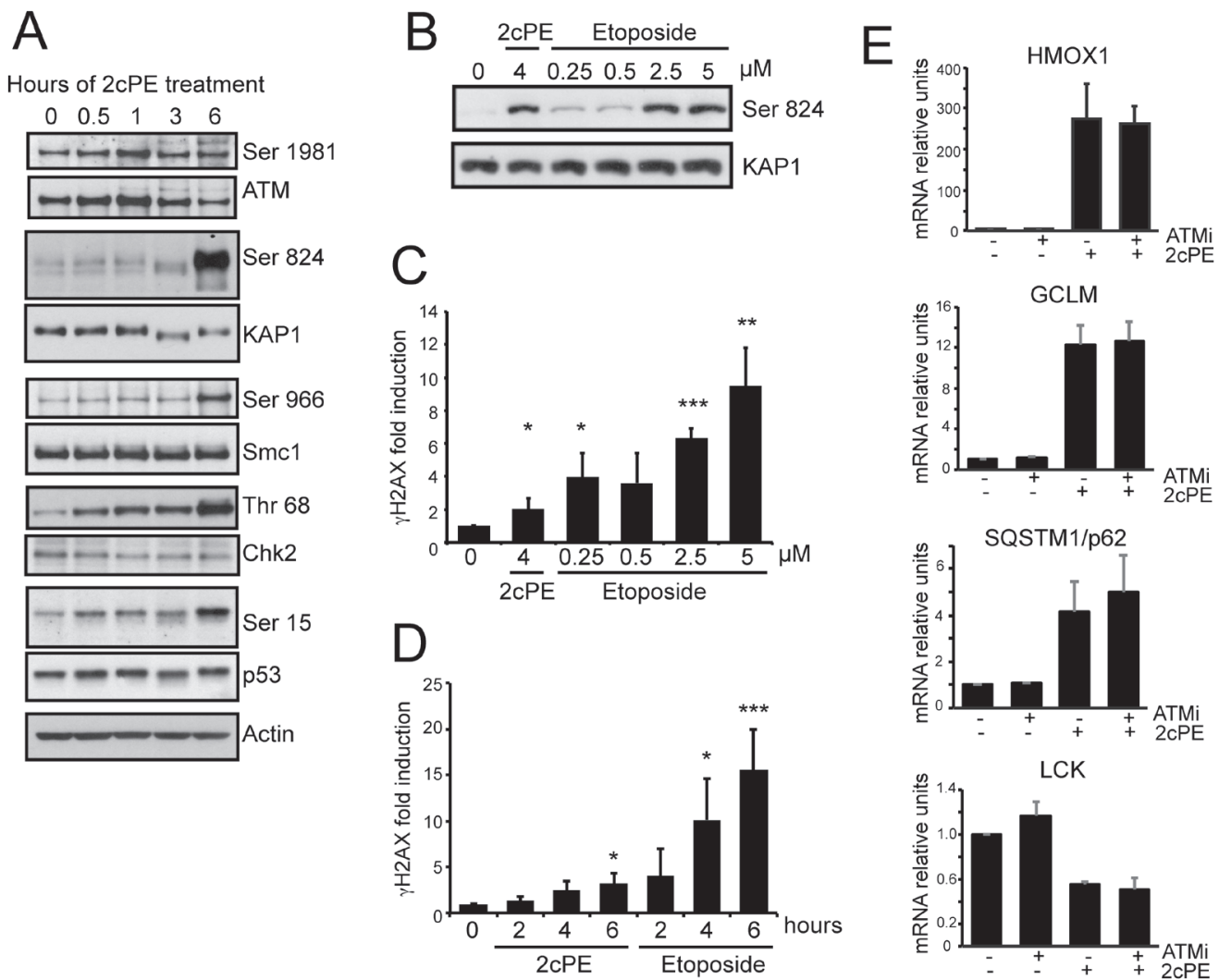

Figure 7: 2cPE activates ATM signaling. A. Activation of the ATM signaling pathway in response to 2cPE treatment. Cellular lysates were generated at the indicated time points and subjected to immunoblot analysis. The detected proteins and their phosphorylated forms are indicated. Actin was used as loading control. B. Immunoblot analysis comparing ATM activation in response to etoposide and 2cPE. KAP1 phosphorylation was used as read-out for ATM activation. MEC-1 cells were treated for $6 \mathrm{~h}$ with the indicated concentrations of the two drugs. C. Quantitative cytofluorimetric analysis of $\gamma \mathrm{H} 2 \mathrm{AX}$ positivity as marker of DNA damage induction. MEC-1 cells were treated for 6 hours with the indicated concentrations of the two drugs. D. Time-course of $\gamma \mathrm{H} 2 \mathrm{AX}$ positivity by quantitative cytofluorimetric analysis. MEC-1 cells were treated for the indicated hours with $4 \mu \mathrm{M}$ of $2 \mathrm{cPE}$ or $2.5 \mu \mathrm{M}$ of etoposide. E. Time-course analysis of HOMX, GCLM, SQSTM and LCK mRNA expression levels in MEC-1 cells treated with $4 \mu \mathrm{M}$ of $2 \mathrm{cPE}$ in the presence of the ATM inhibitor KU55933. Cells were pre-treated for 1 hour with KU-55933 $(10 \mu \mathrm{M})$, next, 2cPE was added for further $6 \mathrm{~h}$. Columns, mean ( $\mathrm{n}=3)$; bars, SD. $*=\mathrm{p}<0.05 ; * *=\mathrm{p}<0.01 ; * * * \mathrm{p}=<0.005$. 


\section{DISCUSSION}

Although bortezomib has proved inefficacy for the treatment of CLL patients [8], the UPS represents a promising therapeutic target and new UPS inhibitors are under evaluation [32-34]. In this manuscript we have demonstrated that 2cPE triggers apoptosis in B-CLL cells and activates multiple transcriptional programs.

The vast majority of DEGs associated to $2 \mathrm{cPE}$ and bortezomib treatments encode for elements of stress response pathways, aimed to sustain cell survival.
Interfering with such adaptive pathways potentiates the pro-death effect of $2 \mathrm{cPE}$. This discovery could help to improve the anti-neoplastic efficiency of these molecules, by applying selective co-treatments.

Interestingly $2 \mathrm{cPE}$ is a stronger inducer of proteotoxic stress compared to bortezomib. Proteotoxic stress is emerging as an attracting druggable response. Malignant cells exhibit higher levels of proteotoxic stress, as a consequence of their higher proliferative and mutational status [35-38]. This peculiarity renders cancer cells more dependent on the UPS and more vulnerable
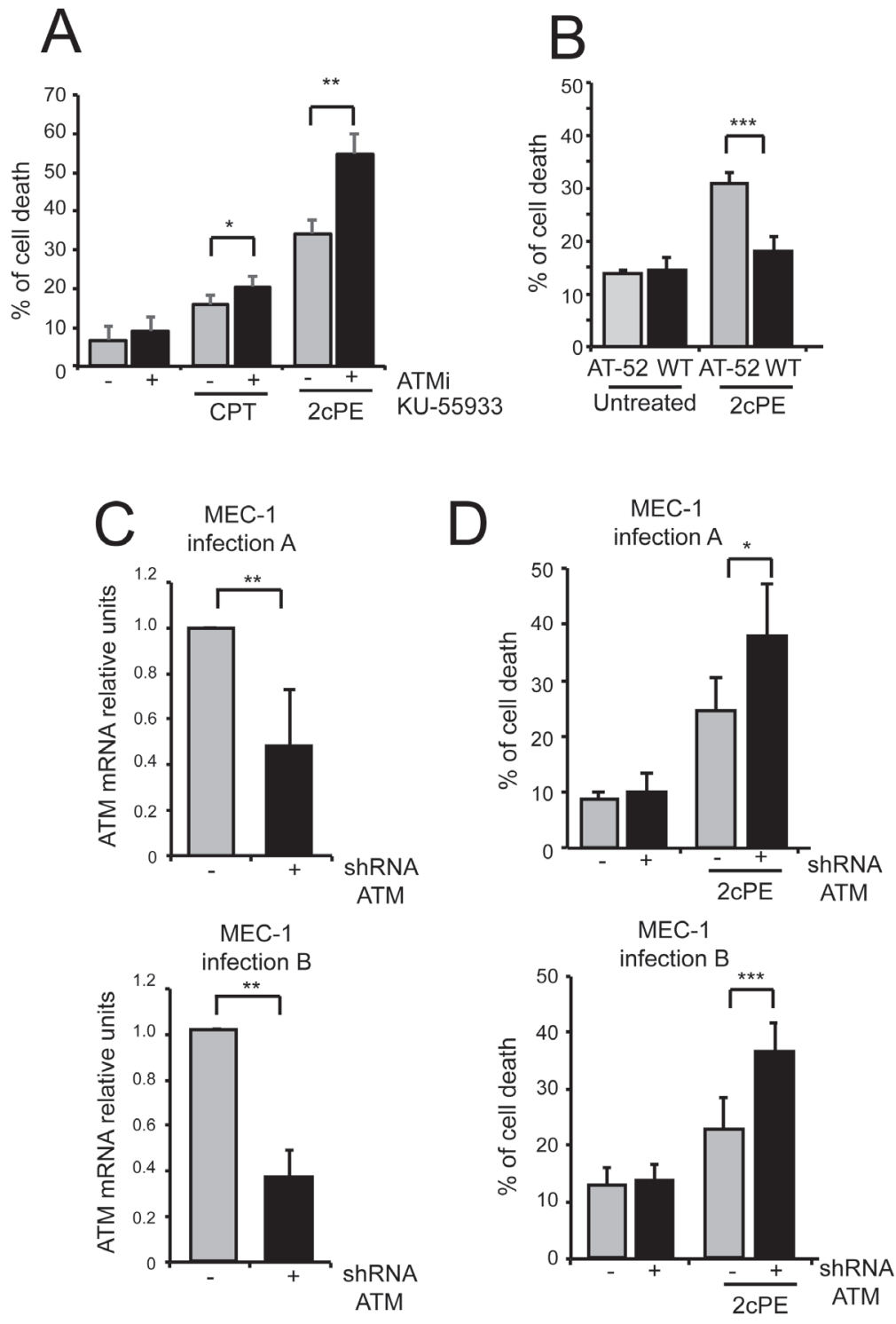

Figure 8: ATM inhibition strengthens apoptosis induced by 2cPE. A. MEC-1 cells were pre-treated for 1 hour with KU-55933 $(10 \mu \mathrm{M})$. Next, $2 \mathrm{cPE}(2 \mu \mathrm{M})$ or camptothecin $(\mathrm{CTP})(50 \mu \mathrm{M})$ were added for further $20 \mathrm{~h}$. Cell death was calculated as percentage of cells positive to PI staining using cytofluorimetric analysis. B. LCL cells WT or AT-52 mutated were treated for $22 \mathrm{~h}$ with $2 \mu \mathrm{M}$ of $2 \mathrm{cPE}$. Cell death was scored by PI staining using cytofluorimetric analysis. C. ATM mRNA levels in MEC-1 cells expressing the shRNA against ATM or the control, as generated by two distinct lentiviral infections. D. MEC-1 cells with down-regulated ATM expression generated after two distinct infections $(\mathrm{A}$ and $\mathrm{B})$ and control cells were treated with $2 \mathrm{cPE}(0.5 \mu \mathrm{M})$ for $6 \mathrm{~h}$. Cell death was calculated as percentage of cells positive to PI staining using cytofluorimetric analysis. Columns, mean $(n=4)$; bars, SD. ${ }^{*}=\mathrm{p}<0.05 ; * *=\mathrm{p}<0.01 ; * * * \mathrm{p}=<0.005$. 
to its inhibitors or to inducers of proteotoxic stress [39, $40]$. We propose that $2 \mathrm{cPE}$ and similar compounds are efficient anti-neoplastic drugs in vivo, because they elicit a vicious cycle, by triggering proteotoxic stress in cancer cells, which already exhibit high level of such stress. By contrast, $2 \mathrm{cPE}$-induced proteotoxic stress is manageable in normal cells, thus explaining the absence of general toxicity in vivo [40-42]. It is possible that $2 \mathrm{cPE}$ and similar compounds, in addition of targeting the catalytic cysteine of isopeptidases, react with and consume the glutathione pool, thus provoking oxidative-stress. In fact, NRF2 is activated and the GSH regenerating system is upregulated in response to $2 \mathrm{cPE}$. Moreover, pre-treatment of G5 with N-acetylcysteine completely abrogates its apoptotic activity (data not shown).

Because of the heterogeneity of this disease [43], some leukemia cells are resistant to $2 \mathrm{cPE}$ treatment. Gene expression profile analysis indicates two different conditions of resistance. In the first case, cells display overt changes in DEGs associated to $2 \mathrm{cPE}$ (patient LLC37). In the second case, which comprises leukemia cells from patients LLC122, LLC195 and LLC270, DEGs changes are dramatically reduced.

The components of the apoptotic machinery in LLC37 cells, (BCL2 family members and caspases) do not evidence alterations in their expression (data not shown). Hence, currently we cannot explain the origin of such resistance. Importantly, LLC37 cells were analogously resistant to bortezomib.

In leukemia cells from patients LLC122, LLC195 and LLC270, resistance is not due to deficit in pro-drug maturation, as recently observed in other cancer cells [20]. Hierarchical gene clustering analysis of the different patientderived B-CLL cells and the presence of the 11q deletion suggested that ATM could be a candidate for such resistant phenotype. The ATM kinase has a well-defined role in sensing DNA double-strand breaks (DSB) and transducing downstream signals that activate the DNA repair and the cell cycle checkpoint machinery [44]. Notably, the ATM signaling pathway was stimulated by $2 \mathrm{cPE}$.

ATM is also activated by oxidative stress, through a mechanism distinct to that of activation by DNA breaks [45]. The activation of the anti-oxidants response and the feeble appearance of DSBs in 2cPE treated cells, suggest that a perturbed redox balance might be responsible for ATM activation [46]. In an unexpected manner, ATM inhibition reinforced apoptosis in $2 \mathrm{cPE}$ treated cells. Hence, ATM cannot be responsible for the apoptotic resistance to $2 \mathrm{cPE}$. Although we do not have an explanation for such resistance, our results disclose a new opportunity for testing $2 \mathrm{cPE}$ in cancer cells that have accumulated mutations in ATM, in p53, or in both genes [47, 48].

In conclusion we have demonstrated that $2 \mathrm{cPE}$ triggers pleiotropic cellular stresses. At first glance induction of multiple stresses does not seem to be attractive for the selective elimination of neoplastic cells, however several recent reports about the effectiveness in animal models of this class of compounds $[12,14,15$, $20]$ justify further studies to improve their anti-neoplastic activities.

\section{MATERIALS AND METHODS}

\section{Patients, cell separation and culture conditions}

The ethic approval for our study was obtained from ethic committee of "Regione Veneto": (Prot.n. 2662P). We obtained peripheral blood from 10 patients that satisfied standard morphological and immunophenotypic criteria for CLL according to the guidelines of the International Workshop on Chronic Lymphocytic Leukemia IWCLL [49]. No patient was previously treated with bortezomib or other proteasome inhibitors. Peripheral blood mononuclear cells (PBMCs) were isolated as previously described [50]. All samples utilized had a CD $19^{+}$B-cell content greater than 95\%. Purified cells were cultured in RPMI-1640 medium supplemented with $10 \%$ heated inactivated fetal calf serum (FCS; Invitrogen, Paisley, UK). Human chronic B-cell leukemia, MEC-1 cells and EBV-immortalized lymphoblastoid cell lines (LCLs) WT and AT52RM and compound heterozygous mutations $7626 \mathrm{C} \rightarrow \mathrm{T} / 8365 \mathrm{del}$ A, were grown under similar conditions. Mediums were supplied with heated inactivated fetal calf serum (FCS; Sigma Aldrich), penicillin (100 U/mL), glutamine (2 $\mathrm{mmol} / \mathrm{L})$, and streptomycin $(100 \mu \mathrm{g} / \mathrm{mL})$.

\section{Reagents and antibodies}

Chemicals used were: bortezomib (LC Laboratories), 2,3-dimethoxy-1,4-naphthoquinone (DMNQ), Propidium Iodide (Sigma Aldrich), buthionine sulfoximine (BSO), 7-cyclopentyl-5-(4-phenoxyphenly)7H-pyrrolo[2,3-d]pyrimidin-4-amine LCK inhibitor (LCKi), 17-(Allylamino)-17-demethoxygeldanamycin (17-AAG) (Cayman Chemicals), ATM inhibitor (KU55933) (Abcam Biochemicals), 2c ((E)-3,5-Bis[(pnitrophenyl)methylidene]-4-hydroxycyclohexanone),

2cPE ((E)-3,5-Bis[(p-nitrophenyl)methylidene]-4oxocyclohexyl polyethyleneglycol succinate). Primary antibodies used were: anti-phospho-Ser139 H2A.X, anti-pKAP-1/TIF1 $\beta$ Ser824 and anti-KAP1/TIF1 $\beta$ (Cell Signaling), anti-actin (a2066 Sigma) anti-NRF2 (Santa Cruz Biotechnology).

\section{RNA expression array and data analysis}

Total RNA was isolated using RNeasy Mini kit (Qiagen). RNA samples concentration and purity (assessed as 260/280 nm and 260/230 nm ratios) were evaluated by NanoDrop ND-1000 spectrophotometer (NanoDrop Technologies; Wilmington, DE), while RNA integrity was assessed by using the Agilent 2100 Bioanalyzer (Agilent Technologies; Waldbrunn, Germany). For gene expression profiling (GEP) cDNA 
synthesis and biotin-labeled target synthesis were performed using the GeneAtlas 3' IVT Express Kit according to the protocol supplied by Affymetrix. The HG-U219 Array Strips (Affymetrix; Santa Clara, CA) hybridization, staining, and scanning were performed by using the GeneAtlas Platform. All the GEP data have been deposited in the NCBI's Gene Expression (GEO) public repository http://www.ncbi.nlm.nih. gov/geo/query/acc.cgi?token=kbapyckufpcdxwh\&ac $\mathrm{c}=\mathrm{GSE74514}$. Data analysis was performed using the paired t-test as previously described [51]. $P$ values were adjusted for multiple testing using the False Discovery Rate method. Differentially expressed genes (DEGs) were selected based on fold change $>1.5$ and $<-1.5$ fold and $P$ values $<0.05$. The analysis of Gene Ontology terms was performed using the DAVID server. DEGs in response to $2 \mathrm{cPE}$ or bortezomib were clustered using hierarchical clustering by computing the Euclidean distance and applying the complete linkage method. For the hierarchical clustering of the gene expression profiles of B-CLL cells from different patients before drug-treatment the average linkage method was used.

\section{RNA extraction and qRT-PCR analysis}

RNA was extracted using Tri-Reagent (Molecular Research Center) and retrotranscribed by using 100U of Moloney murine leukemia virus reverse transcriptase (Invitrogen). The primer sequences used are available upon request. Quantitative reverse transcription-PCR (qRT-PCR) analyses were performed using Bio-Rad CFX96 and SYBR Green technology. HPRT and GAPDH were used as normalizer genes. All reactions were done in triplicate. Data were from al least 3 experiments \pm SD.

\section{Caspase activation assays and cytofluorimetric analysis}

Analysis of caspase-3 activation was performed using Caspase-3 fluorescent assay kit (Cayman chemical). For quantification of cell death, cells were re-suspended in $500 \mu \mathrm{L}$ of PBS and stained with propidium iodide (PI). Fluorescence was determined with a FACScan ${ }^{\mathrm{TM}}$ (Beckman Dickinson). To detect $\mathrm{H} 2 \mathrm{AX}$ phosphorylation cells were fixed in paraformaldehyde $3 \%$ for 20 ' at room temperature, permeabilized with $0.1 \%$ TritonX-100 and incubated with the primary antibody anti-pH2AX for $1 \mathrm{hr}$. After washes, cells were incubated with the secondary antibody anti-rabbit Alexa Fluo-488 (Invitrogen) for 30 min. Results were from al least 3 experiments \pm SD.

\section{Western blotting and lentiviral infections}

Proteins obtained after an SDS denaturating lysis and sonication were transferred to nitrocellulose membrane and incubated with the specific primary antibodies. Secondary antibodies were peroxidase-conjugated goat anti-rabbit or anti-mouse (Sigma). Blots were developed with Super Signal West Dura (Pierce). For stable ATM down-regulation, the vector-based shRNA interference pLenti6/BLOCK-iT-DEST (Invitrogen) was used as previously described [52]. Culture supernatant obtained from transfected recipient 293 cells, containing viral particles, was recovered and used to infect MEC-1 cells.

\section{CONFLICTS OF INTEREST}

The authors declare no conflicts of interest

\section{FINANCIAL SUPPORT}

This work was supported by FIRB (Progetto RBAP11S8C3_002) and by AIRC (Associazione Italiana per la Ricerca sul Cancro) to C.B, L.T. and G.S.

\section{REFERENCES}

1. Billard C, Merhi F, Bauvois B. Mechanistic insights into the antileukemic activity of hyperforin. Curr Cancer Drug Targets. 2013; 13:1-10.

2. Fakler M, Loeder S, Vogler M, Schneider K, Jeremias I, Debatin KM, Fulda S. Small molecule XIAP inhibitors cooperate with TRAIL to induce apoptosis in childhood acute leukemia cells and overcome Bcl-2-mediated resistance. Blood. 2009; 113:1710-22. doi: 10.1182/ blood-2007-09-114314.

3. Smit LA, Hallaert DY, Spijker R, de Goeij B, Jaspers A, Kater AP, van Oers MH, van Noesel CJ, Eldering E. Differential Noxa/Mcl-1 balance in peripheral versus lymph node chronic lymphocytic leukemia cells correlates with survival capacity. Blood. 2007; 109:1660-8.

4. Pepper C, Lin TT, Pratt G, Hewamana S, Brennan P, Hiller L, Hills R, Ward R, Starczynski J, Austen B, Hooper L, Stankovic T, Fegan C. Mcl-1 expression has in vitro and in vivo significance in chronic lymphocytic leukemia and is associated with other poor prognostic markers. Blood. 2008; 112:3807-17. doi: 10.1182/blood-2008-05-157131.

5. Fulda S. Exploiting inhibitor of apoptosis proteins as therapeutic targets in hematological malignancies. Leukemia. 2012; 26:1155-65. doi: 10.1038/leu.2012.4.

6. Kelley TW, Alkan S, Srkalovic G, Hsi ED. Treatment of human chronic lymphocytic leukemia cells with the proteasome inhibitor bortezomib promotes apoptosis. Leuk Res. 2004; 28:845-50.

7. Pahler JC, Ruiz S, Niemer I, Calvert LR, Andreeff M, Keating M, Faderl S, McConkey DJ. Effects of the proteasome inhibitor, bortezomib, on apoptosis in isolated lymphocytes obtained from patients with chronic lymphocytic leukemia. Clin Cancer Res. 2003; 9:4570-7.

8. Faderl S, Rai K, Gribben J, Byrd JC, Flinn IW, O'Brien S, Sheng S, Esseltine DL, Keating MJ. Phase II study of single-agent bortezomib for the treatment of patients with 
fludarabine-refractory B-cell chronic lymphocytic leukemia. Cancer. 2006; 107:916-24.

9. Liu FT, Agrawal SG, Movasaghi Z, Wyatt PB, Rehman IU, Gribben JG, Newland AC, Jia L. Dietary flavonoids inhibit the anticancer effects of the proteasome inhibitor bortezomib. Blood. 2008; 112:3835-46. doi: 10.1182/ blood-2008-04-150227.

10. Arastu-Kapur S, Anderl JL, Kraus M, Parlati F, Shenk KD, Lee SJ, Muchamuel T, Bennett MK, Driessen C, Ball AJ, Kirk CJ. Nonproteasomal targets of the proteasome inhibitors bortezomib and carfilzomib: a link to clinical adverse events. Clin Cancer Res. 2011; 17:2734-43. doi: 10.1158/1078-0432.CCR-10-1950.

11. Aleo E, Henderson CJ, Fontanini A, Solazzo B, Brancolini C. Identification of new compounds that trigger apoptosome-independent caspase activation and apoptosis. Cancer Res. 2006; 66:9235-44.

12. Coughlin K, Anchoori R, Iizuka Y, Meints J, MacNeill L, Vogel RI, Orlowski RZ, Lee MK, Roden RB, Bazzaro M. Small-molecule RA-9 inhibits proteasome-associated DUBs and ovarian cancer in vitro and in vivo via exacerbating unfolded protein responses. Clin Cancer Res. 2014; 20:3174-86. doi: 10.1158/1078-0432.CCR-13-2658.

13. Mullally JE, Fitzpatrick FA. Pharmacophore model for novel inhibitors of ubiquitin isopeptidases that induce p53independent cell death. Mol Pharmacol. 2002; 62:351-8.

14. D'Arcy P, Brnjic S, Olofsson MH, Fryknas M, Lindsten K, De Cesare M, Perego P, Sadeghi B, Hassan M, Larsson R, Linder S. Inhibition of proteasome deubiquitinating activity as a new cancer therapy. Nat Med. 2011; 17:1636-40. doi: 10.1038/nm.2536.

15. Kapuria V, Peterson LF, Fang D, Bornmann WG, Talpaz M, Donato NJ. Deubiquitinase inhibition by smallmolecule WP1130 triggers aggresome formation and tumor cell apoptosis. Cancer Res. 2010; 70:9265-76. doi: 10.1158/0008-5472.CAN-10-1530.

16. Selvendiran K, Kuppusamy ML, Bratasz A, Tong L, Rivera BK, Rink C, Sen CK, Kálai T, Hideg K, Kuppusamy P. Inhibition of vascular smooth-muscle cell proliferation and arterial restenosis by HO-3867, a novel synthetic curcuminoid, through up-regulation of PTEN expression. J Pharmacol Exp Ther. 2009; 329:959-66. doi: 10.1124/jpet.108.150367.

17. Fontanini A, Foti C, Potu H, Crivellato E, Maestro R, Bernardi P, Demarchi F, Brancolini C. The Isopeptidase Inhibitor G5 Triggers a Caspase-independent Necrotic Death in Cells Resistant to Apoptosis: A comparative study with the proteasome inhibitor bortezomib. J Biol Chem. 2009; 284:8369-81. doi: 10.1074/jbc. M806113200.

18. Tomasella A, Blangy A, Brancolini C. A receptorinteracting protein 1 (RIP1)-independent necrotic death under the control of protein phosphatase PP2A that involves the reorganization of actin cytoskeleton and the action of cofilin-1. J Biol Chem. 2014; 289:25699-710. doi: 10.1074/ jbc.M114.575134.
19. Foti C, Florean C, Pezzutto A, Roncaglia P, Tomasella A, Gustincich S, Brancolini C. Characterization of caspase-dependent and caspase-independent deaths in glioblastoma cells treated with inhibitors of the ubiquitinproteasome system. Mol Cancer Ther. 2009; 8:3140-50. doi: 10.1158/1535-7163.MCT-09-0431.

20. Cersosimo U, Sgorbissa A, Foti C, Drioli S, Angelica R, Tomasella A, Picco R, Semrau MS, Storici P, Benedetti F, Berti F, Brancolini C. Synthesis, characterization, and optimization for in vivo delivery of a nonselective isopeptidase inhibitor as new antineoplastic agent. J Med Chem. 2015; 58:1691-704. doi: 10.1021/jm501336h.

21. Oerlemans R, Franke NE, Assaraf YG, Cloos J, van Zantwijk I, Berkers CR, Scheffer GL, Debipersad K, Vojtekova K, Lemos C, van der Heijden JW, Ylstra B, Peters GJ, et al. Molecular basis of bortezomib resistance: proteasome subunit beta5 (PSMB5) gene mutation and overexpression of PSMB5 protein. Blood. 2008; 112:248999. doi: 10.1182/blood-2007-08-104950.

22. Zhu YX, Tiedemann R, Shi CX, Yin H, Schmidt JE, Bruins LA, Keats JJ, Braggio E, Sereduk C, Mousses S, Stewart AK. RNAi screen of the druggable genome identifies modulators of proteasome inhibitor sensitivity in myeloma including CDK5. Blood. 2011; 117:3847-57. doi: 10.1182/ blood-2010-08-304022.

23. Busse A, Kraus M, Na IK, Rietz A, Scheibenbogen C, Driessen C, Blau IW, Thiel E, Keilholz U. Sensitivity of tumor cells to proteasome inhibitors is associated with expression levels and composition of proteasome subunits. Cancer. 2008; 112:659-70. doi: 10.1002/cncr.23224.

24. Gozzelino R, Jeney V, Soares MP. Mechanisms of cell protection by heme oxygenase-1. Annu Rev Pharmacol Toxicol. 2010; 50:323-54. doi: 10.1146/annurev.pharmtox.010909.105600.

25. Nezis IP, Stenmark H. p62 at the interface of autophagy, oxidative stress signaling, and cancer. Antioxid Redox Signal. 2012; 17:786-93. doi: 10.1089/ars.2011.4394.

26. Majolini MB, D'Elios MM, Galieni P, Boncristiano M, Lauria F, Del Prete G, Telford JL, Baldari CT. Expression of the T-cell-specific tyrosine kinase Lck in normal B-1 cells and in chronic lymphocytic leukemia B cells. Blood. 1998; 91:3390-6.

27. Sgorbissa A, Benetti R, Marzinotto S, Schneider C, Brancolini C. Caspase- 3 and caspase- 7 but not caspase- 6 cleave Gas 2 in vitro: implications for microfilament reorganization during apoptosis. J Cell Sci. 1999; 112:4475-82.

28. Ye P, Mimura J, Okada T, Sato H, Liu T, Maruyama A, Ohyama C, Itoh K. Nrf2- and ATF4-dependent upregulation of xCT modulates the sensitivity of T24 bladder carcinoma cells to proteasome inhibition. Mol Cell Biol. 2014; 34:3421-34. doi: 10.1128/MCB.00221-14.

29. Son YO, Pratheeshkumar P, Roy RV, Hitron JA, Wang L, Divya SP, Xu M, Luo J, Chen G, Zhang Z, Shi X. Antioncogenic and oncogenic properties of Nrf2 in arsenicinduced carcinogenesis. J Biol Chem. 2015; 290:27090100. doi: 10.1074/jbc.M115.675371. 
30. Stankovic T, Skowronska A. The role of ATM mutations and $11 \mathrm{q}$ deletions in disease progression in chronic lymphocytic leukemia. Leuk Lymphoma. 2014; 55:122739. doi: $10.3109 / 10428194.2013 .829919$.

31. Takagi M, Delia D, Chessa L, Iwata S, Shigeta T, Kanke Y, Goi K, Asada M, Eguchi M, Kodama C, Mizutani S. Defective control of apoptosis, radiosensitivity, and spindle checkpoint in ataxia telangiectasia. Cancer Res. 1998; 58:4923-9.

32. Gupta SV, Hertlein E, Lu Y, Sass EJ, Lapalombella R, Chen TL, Davis ME, Woyach JA, Lehman A, Jarjoura D, Byrd JC, Lucas DM. The proteasome inhibitor carfilzomib functions independently of p53 to induce cytotoxicity and an atypical NF-kappaB response in chronic lymphocytic leukemia cells. Clin Cancer Res. 2013; 19:2406-19. doi: 10.1158/1078-0432.CCR-12-2754.

33. Crawford LJ, Irvine AE. Targeting the ubiquitin proteasome system in haematological malignancies. Blood Rev. 2013; 27:297-304. doi: 10.1016/j.blre.2013.10.002.

34. Mistry H, Hsieh G, Buhrlage SJ, Huang M, Park E, Cuny GD, Galinsky I, Stone RM, Gray NS, D'Andrea AD, Parmar K. Small-molecule inhibitors of USP1 target ID1 degradation in leukemic cells. Mol Cancer Ther. 2013; 12:2651-62. doi: 10.1158/1535-7163.MCT-13-0103-T.

35. Davis AL, Qiao S, Lesson JL, Rojo de la Vega M, Park SL, Seanez CM, Gokhale V, Cabello CM, Wondrak GT. The quinone methide aurin is a heat shock response inducer that causes proteotoxic stress and Noxa-dependent apoptosis in malignant melanoma cells. J Biol Chem. 2015; 290:162338. doi: 10.1074/jbc.M114.592626.

36. Tan K, Fujimoto M, Takii R, Takaki E, Hayashida N, Nakai A. Mitochondrial SSBP1 protects cells from proteotoxic stresses by potentiating stress-induced HSF1 transcriptional activity. Nat Commun. 2015; 6:6580. doi: 10.1038/ncomms 7580.

37. De Raedt T, Walton Z, Yecies JL, Li D, Chen Y, Malone CF, Maertens O, Jeong SM, Bronson RT, Lebleu V, Kalluri R, Normant E, Haigis MC et al. Exploiting cancer cell vulnerabilities to develop a combination therapy for ras-driven tumors. Cancer Cell. 2011; 20:400-13. doi: 10.1016/j.ccr.2011.08.014.

38. Bazzaro M, Lee MK, Zoso A, Stirling WL, Santillan A, Shih Ie M, Roden RB. Ubiquitin-proteasome system stress sensitizes ovarian cancer to proteasome inhibitor-induced apoptosis. Cancer Res. 2006; 66:3754-63.

39. Bailey CK, Budina-Kolomets A, Murphy ME, Nefedova Y. Efficacy of the HSP70 inhibitor PET-16 in multiple myeloma. Cancer Biol Ther. 2015; 16:1422-6. doi: 10.1080/15384047.2015.1071743.

40. Chitta K, Paulus A, Akhtar S, Blake MK, Caulfield TR, Novak AJ, Ansell SM, Advani P, Ailawadhi S, Sher T, Linder S, Chanan-Khan A. Targeted inhibition of the deubiquitinating enzymes, USP14 and UCHL5, induces proteotoxic stress and apoptosis in Waldenstrom macroglobulinaemia tumour cells. Br J Haematol. 2015; 169:377-90. doi: 10.1111/bjh.13304. Epub 2015 Feb 17.
41. Raj L, Ide T, Gurkar AU, Foley M, Schenone M, Li X, Tolliday NJ, Golub TR, Carr SA, Shamji AF, Stern AM, Mandinova A, Schreiber SL, et al. Selective killing of cancer cells by a small molecule targeting the stress response to ROS. Nature. 2011; 475:231-4. doi: 10.1038/nature10167.

42. Dai C, Dai S, Cao J. Proteotoxic stress of cancer: implication of the heat-shock response in oncogenesis. $\mathrm{J}$ Cell Physiol. 2012; 227:2982-7. doi: 10.1002/jcp.24017.

43. Hallek M. Chronic lymphocytic leukemia: 2015 Update on diagnosis, risk stratification, and treatment. Am J Hematol. 2015; 90:446-60. doi: 10.1002/ajh.23979.

44. Shiloh Y, Ziv Y. The ATM protein kinase: regulating the cellular response to genotoxic stress, and more. Nat Rev Mol Cell Biol. 2013; 14:197-210.

45. Guo Z, Deshpande R, Paull TT. ATM activation in the presence of oxidative stress. Cell Cycle. 2010; 9:4805-11.

46. Cosentino C, Grieco D, Costanzo V. ATM activates the pentose phosphate pathway promoting anti-oxidant defence and DNA repair. EMBO J. 2011; 30:546-55. doi: 10.1038/ emboj.2010.330.

47. Negrini S, Gorgoulis VG, Halazonetis TD. Genomic instability - an evolving hallmark of cancer. Nat Rev Mol Cell Biol. 2010; 11:220-8. doi: 10.1038/nrm2858.

48. Zhou B, Zuo Y, Li B, Wang H, Liu H, Wang X, Qiu X, Hu Y, Wen S, Du J, Bu X. Deubiquitinase inhibition of $19 \mathrm{~S}$ regulatory particles by 4-arylidene curcumin analog AC17 causes NF-kappaB inhibition and p53 reactivation in human lung cancer cells. Mol Cancer Ther. 2013; 12:1381-92. doi: 10.1158/1535-7163.MCT-12-1057.

49. Hallek M, Cheson BD, Catovsky D, Caligaris-Cappio F, Dighiero G, Dohner H, Hillmen P, Keating MJ, Montserrat E, Rai KR, Kipps TJ. Guidelines for the diagnosis and treatment of chronic lymphocytic leukemia: a report from the International Workshop on Chronic Lymphocytic Leukemia updating the National Cancer Institute-Working Group 1996 guidelines. Blood. 2008;111:5446-56. doi: 10.1182/blood-2007-06-093906. Epub 2008 Jan 23.

50. Frezzato F, Trimarco V, Martini V, Gattazzo C, Ave E, Visentin A, Cabrelle A, Olivieri V, Zambello R, Facco M, Zonta F, Cristiani A, Brunati AM, et al. Leukaemic cells from chronic lymphocytic leukaemia patients undergo apoptosis following microtubule depolymerization and Lyn inhibition by nocodazole. Br J Haematol. 2014;165:659-72. doi: 10.1111/bjh.12815.

51. Picco R, Tomasella A, Fogolari F, Brancolini C. Transcriptomic analysis unveils correlations between regulative apoptotic caspases and genes of cholesterol homeostasis in human brain. PLoS One. 2014;9:e110610. doi: 10.1371/journal.pone.0110610.

52. Carlessi L, De Filippis L, Lecis D, Vescovi A, Delia D. DNA-damage response, survival and differentiation in vitro of a human neural stem cell line in relation to ATM expression. Cell Death Differ. 2009;16:795-806. doi: 10.1038/cdd.2009.10. 